\title{
Combination of C-reactive Protein and Monocyte Count Is a Useful Prognostic Indicator for Patients With Colorectal Cancer
}

\author{
MANABU YAMAMOTO, HIROAKI SAITO, KAZUSHI HARA, KEN SUGEZAWA, CHIHIRO UEJIMA, \\ AKIMITSU TANIO, YOICHIRO TADA, KYOICHI KIHARA, TERUHISA SAKAMOTO, \\ SOICHIRO HONJO and YOSHIYUKI FUJIWARA
}

Division of Surgical Oncology, Department of Surgery, School of Medicine, Tottori University Faculty of Medicine, Yonago, Japan

\begin{abstract}
Background/Aim: Several studies have demonstrated the usefulness of $C$-reactive protein (CRP) or cellular components obtained from complete blood count as prognostic indicators in colorectal cancer (CRC) patients. The aim of this study was to investigate the prognostic significance of the combination of CRP and blood cellular components in CRC patients. Patients and Methods: A total of 463 patients who underwent curative surgery for CRC were enrolled in this study. Results: ROC analysis revealed that the values of area under the curve of neutrophil, lymphocyte, platelet, and monocyte counts (MC) for overall survival (OS) were 0.594 , $0.513,0.553$, and 0.625 , respectively. Using cut-off values derived from ROC analysis, patients were divided into the following groups, $C R P^{H i g h}, C R P^{\text {Low }}, \mathrm{MC}^{\mathrm{High}}$, and $M C^{\text {Low }}$. The 5-year OS rates of $C R P^{H i g h}$ and $M C^{H i g h}, C R P^{H i g h}$ and $M C^{\text {Low }}, C R P^{\text {Low }}$ and $M C^{\text {High }}$, and $C R P^{\text {Low }}$ and $M C^{\text {Low }}$ patients were $60.2 \%, 75.7 \%, 82.1 \%$, and $88.3 \%$, respectively $(p<0.0001)$. Multivariate analysis revealed that the combination of serum CRP levels and MC was an independent prognostic indicator. With regard to the cause of death, the combination of CRP and MC was significantly associated with both cancer-related and unrelated death. Conclusion: The combination of CRP and MC is useful in predicting the prognosis in CRC patients.
\end{abstract}

This article is freely accessible online.

Correspondence to: Hiroaki Saito, Division of Surgical Oncology, Department of Surgery, School of Medicine, Tottori University Faculty of Medicine, 36-1 Nishi-cho, Yonago 683-8504, Japan. Tel: +81859386567, Fax: +81859386569, e-mail: sai10@tottorimed.jrc.or.jp

Key Words: Colorectal cancer, C-reactive protein, monocyte count, prognosis.
Colorectal cancer (CRC) is one of the most commonly diagnosed cancers. Although the prognosis of CRC patients has improved with recent advances in surgical techniques and chemotherapy, including molecularly targeted drugs, CRC remains the fourth cause of cancer death worldwide (1). Therefore, identifying factors that are predictive of prognosis is critical for establishing appropriate treatment strategies and improving long-term outcome of CRC patients.

Accumulating evidence has shown that tumor markers (TMs), such as carcinoembryonic antigen (CEA) and carbohydrate antigen 19-9, are useful in predicting long-term survival in CRC patients $(2,3)$. These TMs are frequently used in clinical settings because they can be measured quickly, noninvasively, and relatively inexpensively. While the origin of a TM is the tumor itself, recent studies have demonstrated that host-related indicators that reflect inflammation, nutrition, and immunity are also closely related to the prognosis of CRC patients (4-7).

The host systemic inflammatory response is associated with tumor development and progression. C-reactive protein (CRP) is one of the most frequently used markers for systemic inflammatory response and is a useful prognostic indicator in various types of cancers, including CRC (8-10). Complete blood count (CBC) data is routinely available to clinicians and includes the concentrations of neutrophils, monocytes, and platelets that are closely related to the inflammation status of patients. CBC data have been correlated with the prognosis of cancer patients (11-14). Recently, several indicators, such as neutrophil to lymphocyte ratio, thrombocyte to lymphocyte ratio, and lymphocyte to monocyte ratio, have been developed using CBC data. These indicators are also thought to reflect inflammation and have been associated with prognosis for various cancers (15-18). Furthermore, these indicators seem to be more useful prognostic indicators than the usage of neutrophil, monocyte, or thrombocyte counts. However, the precise combination of 
a

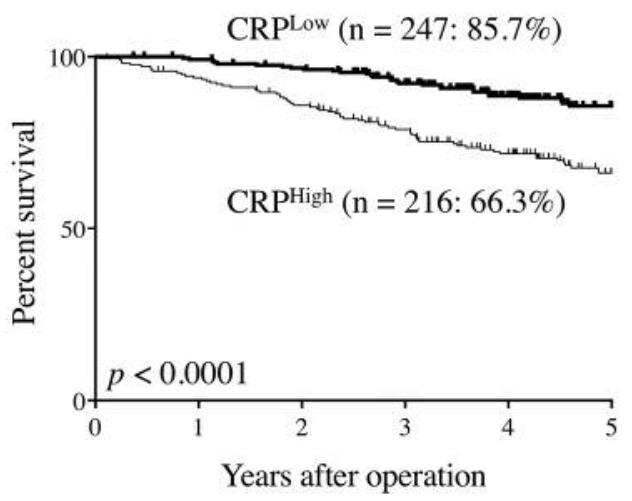

b

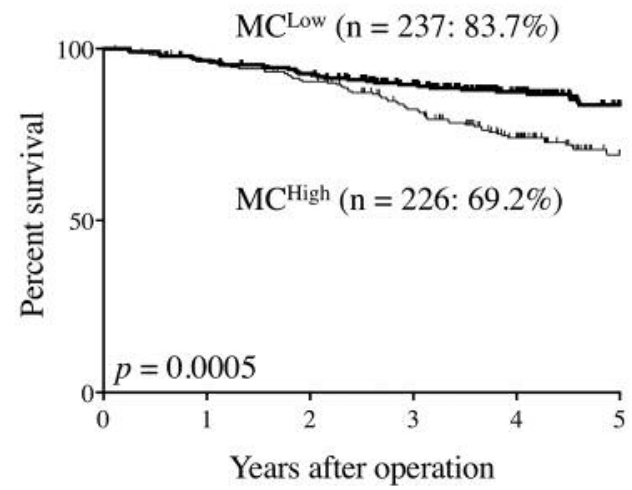

Figure 1. Overall survival curves according to serum $C$-reactive protein levels and peripheral monocyte count. (a) $C$-reactive protein levels. (b) Monocyte count.

inflammation markers that can precisely predict prognosis of CRC patients has remained unclear. Therefore, the aim of this study was to identify the best combination of inflammatory markers that can be obtained from blood analysis as a prognostic indicator in CRC patients.

\section{Patients and Methods}

Patients. This retrospective study included 463 patients who underwent curative surgery for stage I-III CRC at Tottori University Hospital, Japan between January 2007 and December 2015. Patients who underwent emergent surgery or received antibiotics for infectious disease before surgery were excluded. The clinicopathologic findings were assessed according to the eighth edition of the Japanese Classification of Colorectal Carcinoma (19). Patients were periodically examined for early recurrence by diagnostic imaging (chest X-ray, colonoscopy, ultrasonography, and computed tomography). Causes of death and patterns of recurrence were determined by reviewing medical records, including laboratory data, ultrasonography, computed tomography, scintigrams, and laparotomies, or by direct inquiry with family members. Serum CRP and CEA levels and peripheral neutrophil, monocyte, lymphocyte, and platelet counts were measured preoperatively (within 1 month before operation). Institutional review board approval was obtained, and the informed consent requirement was waived for this study.

Ethical approval. All procedures performed in studies involving human participants were in accordance with the ethical standards of the institutional research committee and with the 1964 Helsinki declaration and its later amendments or comparable ethical standards.

Statistical analysis. Categorical variables were compared using Chi square test. Spearman rank correlation coefficient was used to analyze the correlation between serum CRP levels and peripheral monocyte count (MC). The Youden index was calculated using receiver operating characteristic (ROC) analysis to determine an optimal cutoff value for survival analysis. Survival curves were calculated according to the Kaplan-Meier method. Differences between the curves were identified using the log-rank test. Univariate and multivariate analysis of factors considered prognostic of overall survival (OS) were performed using Cox's proportional hazards model. $p<0.05$ was considered to indicate statistically significant difference. Statistical analyses were performed using GraphPad Prism (GraphPad Software, Inc., La Jolla, CA, USA) and Stat View (Abacus Concepts, Inc., Berkeley, CA, USA) software.

\section{Results}

ROC analysis revealed that the area under the curve (AUC) of neutrophil, lymphocyte, monocyte and platelet counts for OS were $0.594,0.513,0.625$, and 0.553 , respectively. Among the blood cellular components that could be obtained from $\mathrm{CBC}, \mathrm{MC}$ had the highest AUC value and was used for subsequent analysis.

ROC analysis indicated that 0.145 and 455.5 had the highest Yoden indices (sensitivity + specificity - 1) for serum CRP levels and MC, respectively, and these values were considered to be optimal cut-off values. Patients were divided into the following groups based on the cut-off values: $\mathrm{CRP}^{\mathrm{High}}$ $(\mathrm{CRP} \geq 0.145 ; \mathrm{n}=216), \mathrm{CRP}^{\mathrm{Low}}(\mathrm{CRP}<0.145 ; \mathrm{n}=247), \mathrm{MC}^{\mathrm{High}}$ $(\mathrm{MC} \geq 455.5 ; \mathrm{n}=226)$, and $\mathrm{MC}^{\mathrm{Low}}(\mathrm{MC}<455.5 ; \mathrm{n}=237)$.

The 5-year OS rates of CRPHigh patients were significantly lower than those of $\mathrm{CRP}^{\mathrm{Low}}$ patients $(66.3 \% \mathrm{vs}$. $85.7 \%$, respectively, $p<0.0001$, Figure 1a). The 5-year OS rates of $\mathrm{MC}^{\mathrm{High}}$ patients were also significantly lower than those of $\mathrm{MC}^{\mathrm{Low}}$ patients $(69.2 \% \mathrm{vs} .83 .7 \%$, respectively, $p=0.0005$, Figure 1b). Figure 2 shows the correlation between serum CRP level and peripheral MC. Although there was a statistically significant positive correlation between them, the correlation coefficient was relatively low $(\mathrm{r}=0.35$, $p<0.0001$; Figure 2). Therefore, the combination of CRP with MC may be more useful in predicting the prognosis of CRC patients than the single use of either CRP or MC. 


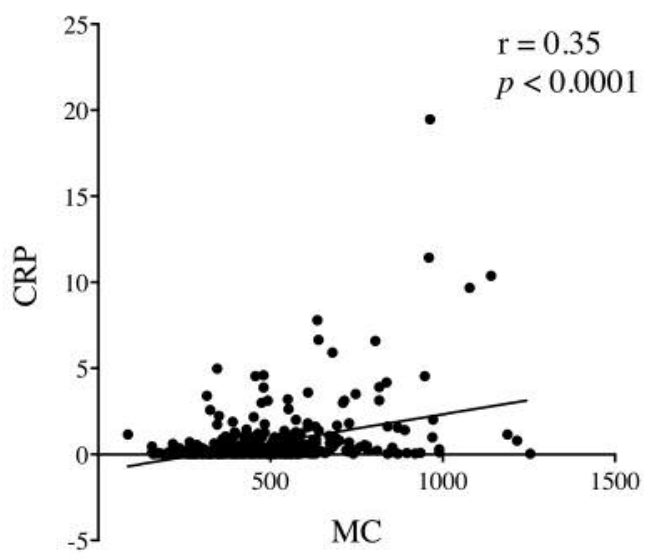

Figure 2. Correlation between serum C-reactive protein (CRP) levels and peripheral monocyte count $(M C)$.

The 5-year OS rates of $\mathrm{CRP}^{\mathrm{High}}$ and $\mathrm{MC}^{\mathrm{High}}$ patients, $\mathrm{CRP}^{\mathrm{High}}$ and $\mathrm{MC}^{\mathrm{Low}}$ patients, $\mathrm{CRP}^{\mathrm{Low}}$ and $\mathrm{MC}^{\mathrm{High}}$ patients, and $\mathrm{CRP}^{\text {Low }}$ and $\mathrm{MC}^{\text {Low }}$ patients were $60.2 \%, 75.7 \%$, $82.1 \%$, and $88.3 \%$, respectively, and the difference was statistically significant $(p<0.0001$; Figure 3$)$. Patients in the $\mathrm{CRP}^{\text {Low }}$ and $\mathrm{MC}^{\text {Low }}, \mathrm{CRP}^{\text {Low }}$ and $\mathrm{MC}^{\mathrm{High}}, \mathrm{CRP}^{\mathrm{High}}$ and $\mathrm{MC}^{\mathrm{Low}}$, and $\mathrm{CRP} \mathrm{P}^{\mathrm{High}}$ and $\mathrm{MC}^{\mathrm{High}}$ groups were then assigned $0,1,2$, and 3 in order of the 5-year OS rates, respectively, to perform ROC analysis according to the previous study (20). ROC curves were constructed for the survival status, and AUC values were compared to assess the discrimination abilities of serum CRP levels, peripheral MC, and the combination of CRP and MC. Among the three prognostic scores, the combination of CRP and MC had the highest AUC value (0.693), followed by CRP (AUC, 0.661) and MC (AUC, 0.625). These findings indicate that the combination of CRP and MC was more useful in predicting the prognosis of CRC patients than the single use of either CRP or MC.

Univariate analysis indicated that age, tumor size, operative approach, depth of tumor invasion, serum CEA level, and the combination of serum CRP level and MC were prognostic indicators (Table I). Parameters with $p<0.1$ in univariate analysis were then examined by multivariate analysis. Multivariate analysis revealed that the combination of serum CRP level and MC was an independent prognostic indicator, along with age, depth of invasion, and serum CEA level (Table I). With regard to the cause of death, the combination of CRP and MC was significantly associated with both cancer-related and unrelated death (Figure 4).

\section{Discussion}

Establishing novel noninvasive prognostic indicators from hematological and serological variables for cancer has been the focus of current research. In this regard, markers that

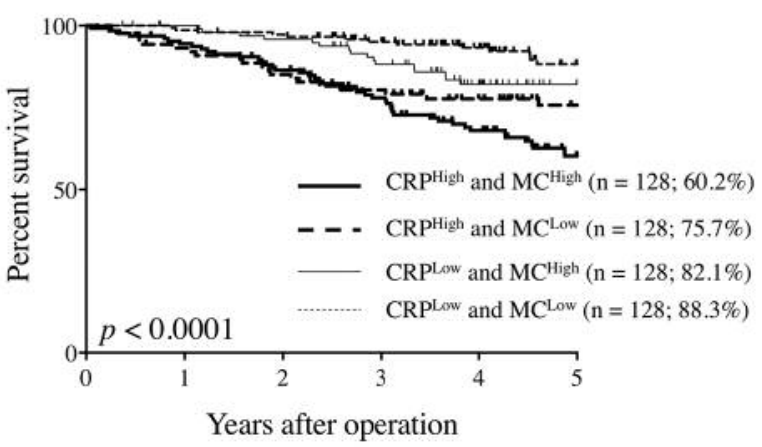

Figure 3. Overall survival curves according to serum C-reactive protein (CRP) levels and peripheral monocyte count (MC).

reflect the inflammation status of patients attract considerable attention, as multiple studies have demonstrated a role for inflammation in tumor progression. CRP is one of the most frequently used serum markers in the evaluation of inflammation status. CRP is an acute-phase reactant that is synthesized by hepatocytes and regulated by proinflammatory cytokines, particularly IL-6 (21). CRC cells produce high levels of IL-6 $(22,23)$, and tumor growth or invasion induces inflammation of the surrounding tissue, also resulting in the production of IL-6. Therefore, increased serum CRP levels are often observed in cancer patients, including CRC patients. Indeed, preoperative CRP levels were shown to be a prognostic indicator in patients with $\mathrm{CRC}$, esophageal cancer, and cervical cancer (8-10). We have also recently demonstrated that the preoperative serum CRP levels are useful in predicting prognosis in CRC patients (7). Furthermore, CRP-based prognostic indicators have been recently developed to predict the prognosis of cancer patients more precisely than CRP alone. The Glasgow prognostic score is CRP-based and is a useful prognostic indicator in CRC patients (24). The CRP to albumin ratio is also a CRP-based prognostic indicator that has been shown to be useful in predicting the prognosis of CRC patients (25). We have recently demonstrated that the platelet $\times C$-reactive protein multiplier value, another CRP-based prognostic indicator, was significantly related to prognosis of gastric cancer patients (26). Because platelet count can be obtained from routine $\mathrm{CBC}$, the evaluation of the platelet $\times \mathrm{C}$-reactive protein multiplier value is convenient and non-invasive. However, other cell data can also be obtained from CBC and are closely related to inflammation status, such as neutrophils and monocytes. These cell counts might also be effective in combination with CRP in predicting the prognosis of CRC patients. ROC analysis demonstrated that the AUC value of $\mathrm{MC}$ was higher than those of neutrophils, lymphocytes, and 
in vivo $34: 299-305(2020)$

Table I. Univariate and multivariate analyses of prognostic factors for overall survival in patients with colorectal cancer.

\begin{tabular}{|c|c|c|c|c|c|c|}
\hline & \multicolumn{3}{|c|}{ Univariate analysis } & \multicolumn{3}{|c|}{ Multivariate analysis } \\
\hline & $p$-Value & HR & $95 \% \mathrm{CI}$ & $p$-Value & HR & $95 \% \mathrm{CI}$ \\
\hline Age $(\geq 70 v s .<70)$ & $<0.0001$ & 2.345 & $1.564-3.5141$ & $<0.0001$ & 2.256 & $1.503-3.384$ \\
\hline Gender (male $v s$. female) & 0.13 & 1.350 & $0.919-1.980$ & & & \\
\hline Tumor size $(\geq 4 \mathrm{~cm}$ vs. $<4 \mathrm{~cm})$ & 0.016 & 1.585 & $1.091-2.304$ & 0.59 & 1.128 & $0.728-1.746$ \\
\hline Tumor location (colon $v s$. rectum) & 0.16 & 1.333 & $0.890-1.996$ & & & \\
\hline Histology (undifferentiated $v s$. differentiated) ${ }^{\mathrm{a}}$ & 0.47 & 1.236 & $0.693-2.208$ & & & \\
\hline Operative approach (open $v s$. laparoscopy) & 0.0001 & 2.129 & $1.442-3.142$ & 0.064 & 1.473 & $0.978-2.218$ \\
\hline Depth of invasion (T3/T4 vs. T1 /T2) $)^{\mathrm{b}}$ & 0.0002 & 2.506 & $1.558-4.032$ & 0.045 & 1.754 & $1.013-3.040$ \\
\hline Lymph node metastasis (present $v s$. absent) & 0.14 & 1.337 & $0.907-1.973$ & & & \\
\hline Lymphatic invasion $(1 \mathrm{y} 2 / 3 \text { vs. 1y } 0 / 1)^{\mathrm{c}}$ & 0.11 & 1.364 & $0.938-1.980$ & & & \\
\hline Vascular invasion $(\mathrm{v} 2 / 3 v s . \vee 0 / 1)^{\mathrm{d}}$ & 0.11 & 1.383 & $0.939-2.037$ & & & \\
\hline CEA level ( $\geq 5 \mathrm{ng} / \mathrm{ml} v s .<5 \mathrm{ng} / \mathrm{ml})$ & $<0.0001$ & 2.478 & $1.703-3.606$ & 0.0016 & 1.899 & $1.277-2.826$ \\
\hline CRP level and $\mathrm{MC}^{\mathrm{e}}$ & $<0.0001$ & & & & 0.0004 & \\
\hline $\mathrm{CRP}^{\mathrm{High}} / \mathrm{MC}^{\mathrm{High}}$ vs. $\mathrm{CRP}^{\mathrm{Low}} / \mathrm{MC}^{\mathrm{Low}}$ & $<0.0001$ & 3.914 & $2.233-6.862$ & 0.0002 & 2.985 & $1.681-5.299$ \\
\hline $\mathrm{CRPHigh} / \mathrm{MC}^{\text {Low }}$ vs. CRPLow/MC Low & 0.0061 & 2.477 & $1.291-4.630$ & 0.2 & 1.549 & $0.793-3.026$ \\
\hline CRPLow/MCHigh $v s . \mathrm{CRP}^{\mathrm{Low}} / \mathrm{MC}^{\text {Low }}$ & 0.051 & 1.923 & $0.996-3.712$ & 0.19 & 1.564 & $0.807-3.030$ \\
\hline
\end{tabular}

CEA: Carcinoembryonic antigen; CRP: C-reactive protein; MC: monocyte count; HR: hazard ratio; CI: confidence interval. aDifferentiated: papillary or tubular adenocarcinoma; undifferentiated: poorly differentiated, mucinous adenocarcinoma, or signet-ring cell carcinoma; ${ }^{\mathrm{T}} \mathrm{T}$, tumor invasion of the lamina propria or submucosa; T2, tumor invasion of the muscularis propria; T3, tumor invasion of the subserosa or within adventitia; T4, tumor penetration of the serosa or tumor invasion of adjacent organs; ${ }^{\mathrm{C}} \mathrm{Ly} 0-\mathrm{Ly} 3$, grade of lymphatic invasion; ${ }^{\mathrm{d} V 0} \mathrm{~V} \mathrm{~V} 1$, grade of vascular invasion; ${ }^{e} \mathrm{CRPH}^{\mathrm{High}}$ or CRPLow: serum CRP level $\geq$ or $<0.145$ (respectively); MCHigh or MCLow: peripheral MC $\geq$ or $<455.5$ (respectively).

platelet counts. The prognosis of $\mathrm{MC}^{\mathrm{High}}$ patients was significantly worse than that $\mathrm{MC}^{\mathrm{Low}}$ patients. Accumulating studies have suggested that increased MC could be an indicator of various inflammatory diseases $(27,28)$. In addition, monocytes suppress the host immune response to cancer. In this regard, we have previously demonstrated that peripheral monocytes have increased PD-L1 expression, the ligand of PD-1, in gastric cancer patients (29). Mounting evidence suggests that PD-L1 expression on solid tumors dampens antitumor T-cell responses (30-35) because PD-L1 delivers a co-inhibitory signal to $\mathrm{T}$ cells upon binding to PD1 , which results in impaired function of $\mathrm{T}$ cells. Other studies have demonstrated that cytotoxic tumor-infiltrating $\mathrm{T}$ lymphocytes and tumor-infiltrating CD45RO+ memory $\mathrm{T}$ cells are closely associated with prognosis in cancer patients $(36$, 37). It is likely that PD-L1-expressing monocytes dampen their function, which results in poor prognosis. Furthermore, a recent study has shown that tumor-associated macrophages expressed PD-1 as well as PD-L1, and PD-1 expression in tumor-associated macrophages correlates negatively with phagocytic potency against tumor cells, which is closely associated with impaired tumor immunity (38). These findings indicated that monocytes are closely associated with both inflammation status and immunosuppression in cancer patients and supported the association between high MC and poor prognosis in this study.

Prediction of postoperative prognosis in CRC patients is important in determining treatment strategy. Both CRP and
$\mathrm{MC}$ are closely related to patient inflammation status and our study revealed a significant positive correlation between CRP and MC. However, the correlation coefficient was relatively low. Therefore, we considered that the combination of CRP with MC was more useful in predicting the prognosis of CRC patients than either CRP or MC alone. ROC analysis revealed that the combination of $\mathrm{CRP}$ and $\mathrm{MC}$ had the highest AUC value compared with CRP or MC alone. These findings indicated that the combination of CRP and MC was more useful for predicting the prognosis of CRC patients than the single use of CRP or MC. Furthermore, multivariate analysis revealed that the combination of CRP and MC was an independent prognostic indicator. Recent progress in chemotherapy has improved the prognosis of unresectable advanced and recurrent CRC (39), while early detection of recurrence has been shown to increase survival after curative colectomy for CRC $(40,41)$. Therefore, the identification of indicators that accurately predict prognosis in CRC patients is critical. The combination of CRP and MC may help in detecting patients who are at high risk of recurrence and need intensive follow-up even after curative surgery.

With regard to the cause of death, the combination of CRP and MC was closely associated with not only cancerrelated death but also cancer unrelated death. The incidence of CRC among the elderly has been increasing in Japan due to the extended life span of the general population. Similar trends are noted worldwide (42). As the functions of various organs are often compromised with age, it is extremely 
a

Cancer-related death

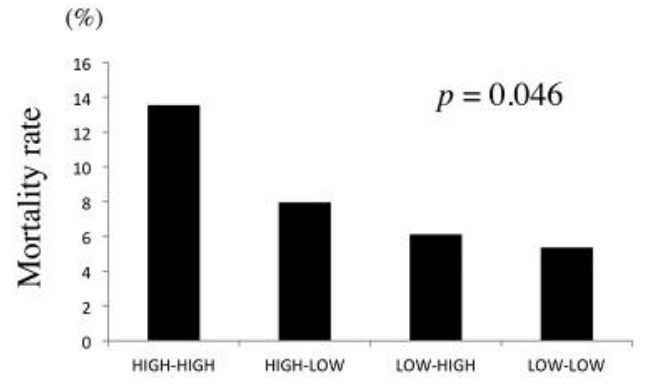

b Cancer-unrelated death

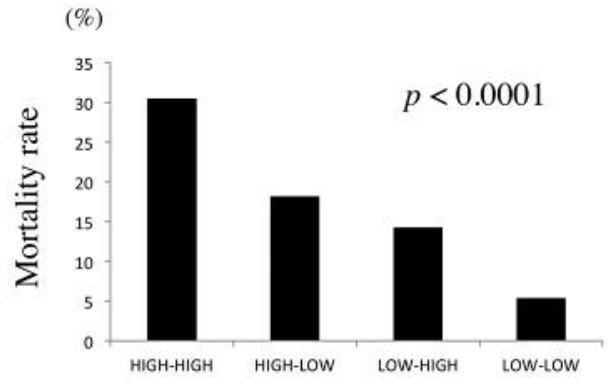

Figure 4. Mortality rates according to serum C-reactive protein levels and peripheral monocyte count. (a) Cancer-related death. (b) Cancer-unrelated death.

important to consider patient-related factors, including the presence of comorbidity, as well as cancer-related factors when deciding the treatment strategy for elderly CRC patients. However, deciding the treatment strategy in elderly patients can be difficult. The combination of CRP and MC may be helpful for surgeons to establish treatment strategies in elderly CRC patients.

Our study has some limitations. First, some bias was present because the study was retrospective. Second, the optimal cut-off values for CRP and MC remain unclear and may be different in various types of cancers. Third, the number of patients included in the current study is small. Therefore, these results must be confirmed in a large-scale trial.

In conclusion, the combination of CRP and MC is useful in predicting the prognosis in $\mathrm{CRC}$ patients. Because measuring serum CRP level and MC is quick, easy, and noninvasive, the combination of CRP and MC may be a useful prognostic indicator in routine clinical settings and may be helpful for surgeons to make decisions on treatment strategy in CRC patients.

\section{Conflicts of Interest}

The Authors declare that they have no conflicts of interest regarding this study.

\section{Authors' Contributions}

Study conception and design: Hiroaki Saito and Manabu Yamamoto; Acquisition of data: Hiroaki Saito, Manabu Yamamoto, Kazushi Hara, Ken Sugezawa, Chihiro Uejima, Akimitsu Tanio, Yoichiro Tada, Kyoichi Kihara, Teruhisa Sakamoto, Soichiro Honjo; Analysis and interpretation of data: Hiroaki Saito and Manabu Yamamoto; Drafting of manuscript: Hiroaki Saito and Manabu Yamamoto; Critical revision: Hiroaki Saito and Yoshiyuki Fujiwara; Final approval of the article: all Authors.

\section{Acknowledgements}

The Authors thank Edanz Group (www.edanzediting.com/ac) for editing a draft of this manuscript.

\section{Funding}

The Authors received no grants, equipment or funding for this study.

\section{References}

1 Torre LA, Bray F, Siegel RL, Ferlay J, Lortet-Tieulent J and Jemal A: Global cancer statistics, 2012. CA Cancer J Clin 65(2): 87-108, 2015. PMID: 25651787. DOI: 10.3322/caac.21262

2 Compton CC, Fielding LP, Burgart LJ, Conley B, Cooper HS, Hamilton SR, Hammond ME, Henson DE, Hutter RV, Nagle RB, Nielsen ML, Sargent DJ, Taylor CR, Welton M and Willett C: Prognostic factors in colorectal cancer. College of american pathologists consensus statement 1999. Arch Pathol Lab Med 124(7): 979-994, 2000. PMID: 10888773. DOI: 10.1043/00039985(2000)124<0979:pficc>2.0.co;2

3 Filella X, Molina R, Grau JJ, Pique JM, Garcia-Valdecasas JC, Astudillo E, Biete A, Bordas JM, Novell A and Campo E: Prognostic value of ca 19.9 levels in colorectal cancer. Ann Surg 216(1): 55-59, 1992. PMID: 1632702. DOI: 10.1097/00000658199207000-00008

4 Tanio A, Saito H, Uejima C, Takaya S, Yamamoto M, Tokuyasu N, Sakamoto T, Honjo S, Ashida K and Fujiwara Y: A prognostic index for colorectal cancer based on preoperative absolute lymphocyte, monocyte, and neutrophil counts. Surg Today 49(3): 245-253, 2019. PMID: 30382360. DOI: 10.1007/s00595-0181728-6

5 Yamamoto M, Saito H, Uejima C, Tanio A, Tada Y, Matsunaga T, Sakamoto T, Honjo S, Ashida K and Fujiwara Y: Combination of serum albumin and cholinesterase levels as prognostic indicator in patients ith colorectal cancer. Anticancer Res 39(2): 1085-1090, 2019. PMID: 30711999. DOI: 10.21873/anticanres.13217

6 Yamamoto M, Saito H, Uejima C, Tanio A, Takaya S, Ashida K and Fujiwara Y: Combined pre- and postoperative lymphocyte count accurately predicts outcomes of patients with colorectal 
cancer. Dig Surg 36(6): 487-494, 2019. PMID: 30219805. DOI: $10.1159 / 000492340$

7 Yamamoto M, Saito H, Uejima C, Tanio A, Takaya S, Sakamoto T, Honjo S, Maeta Y, Ashida K and Fujiwara Y: Prognostic value of the combination of pre- and postoperative c-reactive protein in colorectal cancer patients. Surg Today 48(11): 986-993, 2018. PMID: 30962754. DOI: 10.1007/s00595-018-1689-9

8 Nielsen HJ, Christensen IJ, Sorensen S, Moesgaard F and Brunner N: Preoperative plasma plasminogen activator inhibitor type- 1 and serum c-reactive protein levels in patients with colorectal cancer. The ranx05 colorectal cancer study group. Ann Surg Oncol 7(8): 617-623, 2000. PMID: 11005561. DOI: $10.1007 / \mathrm{bf0} 2725342$

9 Gockel I, Dirksen K, Messow CM and Junginger T: Significance of preoperative c-reactive protein as a parameter of the perioperative course and long-term prognosis in squamous cell carcinoma and adenocarcinoma of the oesophagus. World $\mathrm{J}$ Gastroenterol 12(23): 3746-3750, 2006. PMID: 16773693. DOI: 10.3748/wjg.v12.i23.3746

10 Polterauer S, Grimm C, Tempfer C, Sliutz G, Speiser P, Reinthaller A and Hefler LA: C-reactive protein is a prognostic parameter in patients with cervical cancer. Gynecol Oncol 107(1): 114-117, 2007. PMID: 17617445. DOI: 10.1016/j.ygyno. 2007.06.001

11 Watt DG, Martin JC, Park JH, Horgan PG and McMillan DC: Neutrophil count is the most important prognostic component of the differential white cell count in patients undergoing elective surgery for colorectal cancer. Am J Surg 210(1): 24-30, 2015. PMID: 25842358. DOI: 10.1016/j.amjsurg.2014.12.031

12 Clark EJ, Connor S, Taylor MA, Madhavan KK, Garden OJ and Parks RW: Preoperative lymphocyte count as a prognostic factor in resected pancreatic ductal adenocarcinoma. HPB (Oxford) 9(6): 456-460, 2007. PMID: 18345294. DOI: 10.1080/ 13651820701774891

13 Leitch EF, Chakrabarti M, Crozier JE, McKee RF, Anderson JH, Horgan PG and McMillan DC: Comparison of the prognostic value of selected markers of the systemic inflammatory response in patients with colorectal cancer. Br J Cancer 97(9): 1266-1270, 2007. PMID: 17923866. DOI: 10.1038/sj.bjc.6604027

14 Ikeda M, Furukawa H, Imamura H, Shimizu J, Ishida H, Masutani S, Tatsuta M and Satomi T: Poor prognosis associated with thrombocytosis in patients with gastric cancer. Ann Surg Oncol 9(3): 287-291, 2002. PMID: 11923136. DOI: 10.1007/ bf02573067

15 McMillan DC, Crozier JE, Canna K, Angerson WJ and McArdle CS: Evaluation of an inflammation-based prognostic score (gps) in patients undergoing resection for colon and rectal cancer. Int J Colorectal Dis 22(8): 881-886, 2007. PMID: 17245566. DOI: $10.1007 / \mathrm{s} 00384-006-0259-6$

16 Walsh SR, Cook EJ, Goulder F, Justin TA and Keeling NJ: Neutrophil-lymphocyte ratio as a prognostic factor in colorectal cancer. J Surg Oncol 91(3): 181-184, 2005. PMID: 16118772. DOI: $10.1002 /$ jso.20329

17 Tan D, Fu Y, Tong W and Li F: Prognostic significance of lymphocyte to monocyte ratio in colorectal cancer: A metaanalysis. Int J Surg 55: 128-138, 2018. PMID: 29807167. DOI: 10.1016/j.ijsu.2018.05.030

18 Gu X, Gao XS, Cui M, Xie M, Peng C, Bai Y, Guo W, Han L, $\mathrm{Gu} \mathrm{X}$ and Xiong $\mathrm{W}$ : Clinicopathological and prognostic significance of platelet to lymphocyte ratio in patients with gastric cancer. Oncotarget 7(31): 49878-49887, 2016. PMID: 27409665. DOI: 10.18632 /oncotarget. 10490

19 Rectum JSfCotCa: Japanese classification of colorectal carcinoma. Kanehara: Tokyo, 2013.

20 Haruki K, Shiba H, Shirai Y, Horiuchi T, Iwase R, Fujiwara Y, Furukawa $\mathrm{K}$, Misawa $\mathrm{T}$ and Yanaga $\mathrm{K}$ : The c-reactive protein to albumin ratio predicts long-term outcomes in patients with pancreatic cancer after pancreatic resection. World J Surg 40(9): 2254-2260, 2016. PMID: 26956901. DOI: 10.1007/s00268-0163491-4

21 Morris-Stiff G, Gomez D and Prasad KR: C-reactive protein in liver cancer surgery. Eur J Surg Oncol 34(7): 727-729, 2008. PMID: 18356004. DOI: 10.1016/j.ejso.2008.01.016

$22 \mathrm{Li}$ YY, Hsieh LL, Tang RP, Liao SK and Yeh KY: Interleukin-6 (il-6) released by macrophages induces il- 6 secretion in the human colon cancer ht-29 cell line. Hum Immunol 70(3): 151-158, 2009. PMID: 19272324. DOI: 10.1016/j.humimm.2009.01.004

23 Chung YC, Chaen YL and Hsu CP: Clinical significance of tissue expression of interleukin-6 in colorectal carcinoma. Anticancer Res 26(5b): 3905-3911, 2006. PMID: 17094421.

24 Ishizuka M, Nagata H, Takagi K, Iwasaki Y and Kubota K: Inflammation-based prognostic system predicts postoperative survival of colorectal cancer patients with a normal preoperative serum level of carcinoembryonic antigen. Ann Surg Oncol 19(11): 3422-3431, 2012. PMID: 22576063. DOI: 10.1245/ s10434-012-2384-5

25 Shibutani M, Maeda K, Nagahara H, Iseki Y, Ikeya T and Hirakawa K: Prognostic significance of the preoperative ratio of c-reactive protein to albumin in patients with colorectal cancer. Anticancer Res 36(3): 995-1001, 2016. PMID: 26976989.

26 Saito H, Kono Y, Murakami Y, Shishido Y, Kuroda H, Matsunaga T, Fukumoto Y, Osaki T, Ashida K and Fujiwara Y: Prognostic significance of platelet-based inflammatory indicators in patients with gastric cancer. World J Surg 42(8): 2542-2550, 2018. PMID: 29464343. DOI: $10.1007 / \mathrm{s} 00268-018-4527-8$

27 Gordon S and Taylor PR: Monocyte and macrophage heterogeneity. Nat Rev Immunol 5(12): 953-964, 2005. PMID: 16322748. DOI: $10.1038 /$ nri1733

28 Auffray C, Sieweke MH and Geissmann F: Blood monocytes: Development, heterogeneity, and relationship with dendritic cells. Annu Rev Immunol 27: 669-692, 2009. PMID: 19132917. DOI: 10.1146/annurev.immunol.021908.132557

29 Matsunaga T, Saito H and Ikeguchi M: Increased b7-h1 and b7h4 expressions on circulating monocytes and tumor-associated macrophages are involved in immune evasion in patients with gastric cancer. Yonago Acta Med 54(1): 1-10, 2011. PMID: 24031123.

30 Dong H, Zhu G, Tamada K and Chen L: B7-h1, a third member of the b7 family, co-stimulates t-cell proliferation and interleukin-10 secretion. Nat Med 5(12): 1365-1369, 1999. PMID: 10581077 . DOI: $10.1038 / 70932$

31 Keir ME, Freeman GJ and Sharpe AH: Pd-1 regulates selfreactive cd8 $+\mathrm{t}$ cell responses to antigen in lymph nodes and tissues. J Immunol 179(8): 5064-5070, 2007. PMID: 17911591.

32 Blank C, Brown I, Peterson AC, Spiotto M, Iwai Y, Honjo T and Gajewski TF: Pd-11/b7h-1 inhibits the effector phase of tumor rejection by $\mathrm{t}$ cell receptor (tcr) transgenic $\mathrm{cd} 8+\mathrm{t}$ cells. Cancer Res 64(3): 1140-1145, 2004. PMID: 14871849.

33 Curiel TJ, Wei S, Dong H, Alvarez X, Cheng P, Mottram P, Krzysiek R, Knutson KL, Daniel B, Zimmermann MC, David 
O, Burow M, Gordon A, Dhurandhar N, Myers L, Berggren R, Hemminki A, Alvarez RD, Emilie D, Curiel DT, Chen L and Zou W: Blockade of b7-h1 improves myeloid dendritic cellmediated antitumor immunity. Nat Med 9(5): 562-567, 2003. PMID: 127044383. DOI: 10.1038/nm863

34 Hirano F, Kaneko K, Tamura H, Dong H, Wang S, Ichikawa M, Rietz C, Flies DB, Lau JS, Zhu G, Tamada K and Chen L: Blockade of b7-h1 and pd-1 by monoclonal antibodies potentiates cancer therapeutic immunity. Cancer Res 65(3): 1089-1096, 2005. PMID: 15705911.

35 Strome SE, Dong H, Tamura H, Voss SG, Flies DB, Tamada K, Salomao D, Cheville J, Hirano F, Lin W, Kasperbauer JL, Ballman KV and Chen L: B7-h1 blockade augments adoptive tcell immunotherapy for squamous cell carcinoma. Cancer Res 63(19): 6501-6505, 2003. PMID: 14559843

36 Wakatsuki K, Sho M, Yamato I, Takayama T, Matsumoto S, Tanaka T, Migita K, Ito M, Hotta K and Nakajima Y: Clinical impact of tumor-infiltrating cd45ro(+) memory t cells on human gastric cancer. Oncol Rep 29(5): 1756-1762, 2013. PMID: 23440298. DOI: $10.3892 /$ or.2013.2302

37 Lohneis P, Sinn M, Bischoff S, Juhling A, Pelzer U, Wislocka L, Bahra M, Sinn BV, Denkert C, Oettle H, Blaker H, Riess H, Johrens $\mathrm{K}$ and Striefler JK: Cytotoxic tumour-infiltrating $\mathrm{t}$ lymphocytes influence outcome in resected pancreatic ductal adenocarcinoma. Eur J Cancer 83: 290-301, 2017. PMID: 28772128. DOI: 10.1016/j.ejca.2017.06.016

38 Gordon SR, Maute RL, Dulken BW, Hutter G, George BM, McCracken MN, Gupta R, Tsai JM, Sinha R, Corey D, Ring AM, Connolly AJ and Weissman IL: Pd-1 expression by tumourassociated macrophages inhibits phagocytosis and tumour immunity. Nature 545(7655): 495-499, 2017. PMID: 28514441. DOI: $10.1038 /$ nature22396
39 Jawed I, Wilkerson J, Prasad V, Duffy AG and Fojo T: Colorectal cancer survival gains and novel treatment regimens: A systematic review and analysis. JAMA Oncol 1(6): 787-795, 2015. PMID: 26181239. DOI: 10.1001/jamaoncol.2015.1790

40 Fora A, Patta A, Attwood K, Wilding G and Fakih M: Intensive radiographic and biomarker surveillance in stage ii and iii colorectal cancer. Oncology 82(1): 41-47, 2012. PMID: 22286543. DOI: $10.1159 / 000333855$

41 Pita-Fernandez S, Alhayek-Ai M, Gonzalez-Martin C, LopezCalvino B, Seoane-Pillado $\mathrm{T}$ and Pertega-Diaz S: Intensive follow-up strategies improve outcomes in nonmetastatic colorectal cancer patients after curative surgery: A systematic review and meta-analysis. Ann Oncol 26(4): 644-656, 2015. PMID: 25411419. DOI: 10.1093/annonc/mdu543

42 Teriokhin AT, Budilova EV, Thomas F and Guegan JF: Worldwide variation in life-span sexual dimorphism and sexspecific environmental mortality rates. Hum Biol 76(4): 623641, 2004. PMID: 15754977.
Received October 6, 2019

Revised October 24, 2019

Accepted October 25, 2019 